\title{
¿FANÁTICAS, MATERNALES O FEMINISTAS? MONJAS Y CONGREGACIONISTAS EN LA ESPAÑA DECIMONÓNICA
}

\author{
POR \\ Raúl Mínguez Blasco \\ Universidad del País Vasco / Euskal Herriko Unibertsitatea* \\ raulmb22@hotmail.com
}

\section{RESUMEN}

Uno de los fenómenos más destacados de la feminización del catolicismo durante el siglo XIX fue el notable aumento de las congregaciones femeninas, que se unieron a las más tradicionales órdenes de clausura. Los modelos de feminidad de la época tendieron a imaginar a las mujeres religiosas, bien como sujetos débiles y fanatizados por influencia de sus confesores, bien como cándidos ángeles maternales que atendían de forma desinteresada a los más necesitados. Ambas construcciones ocultaban los aspectos más rupturistas abiertos por las congregaciones femeninas y, en especial, por sus superioras generales. Ambición, autoridad y liderazgo fueron algunos de los principios que caracterizaron las vidas de estas mujeres. A través de los casos de dos fundadoras de congregaciones reflexionaremos sobre su capacidad de agencia y discutiremos hasta qué punto pueden ser calificadas estas mujeres como feministas.

PALABRAS CLAVE: Feminización del catolicismo, monjas de clausura, congregacionistas, imaginario, discurso, agencia, feminismo.

\section{FANATIC, MATERNAL OR FEMINIST? NUNS AND CONGREGATIONISTS IN $19^{\text {TH }}$ CENTURY SPAIN}

\section{ABSTRACT}

One of the most important aspects of Catholic feminization in $19^{\text {th }}$ century was the notable increase of female congregations, which joined to the most traditional enclosed orders. The femininity models of this time tended to imagine religious women, either as weak and fanatic individuals because of their confessors' influence, or as innocent maternal angels who assisted to needy people in a selfless way. Both constructions hid the most radical side of female congregations and especially of their mother superiors. Ambition, authority and leadership were some of the elements that characterized these women lives. Through the cases of two congregation founders, I will reflect on their agency and discuss if these women can be qualified as feminists.

KEY WORDS: Catholic feminization, nuns, congregationists, imaginary, discourse, agency, feminism.

$\begin{array}{lr}\text { Recibido/Received } & 03-02-2014 \\ \text { Aceptado/Accepted } & 25-08-2015\end{array}$

\footnotetext{
El presente trabajo se inscribe dentro del grupo de investigación "La experiencia de la sociedad moderna en España entre 1870 y 1990 ", de la Universidad del País Vasco (UPV/EHU), financiado por GIU 14/04 y el proyecto del MICINN HAR2012-37959-C02-01. El autor también forma parte del proyecto HAR2014-53802-P, financiado por el MINECO. La publicación de este trabajo ha sido posible gracias a un contrato de investigación de carácter postdoctoral concedido en el marco de la convocatoria de ayudas para la especialización de personal investigador doctor del Vicerrectorado de Investigación de la UPV/EHU de 2014.
} 
Hay siempre una diferencia notable de la dureza de un hombre a la crueldad de una mujer. ¿Cuál creéis que es la más fiel encarnación del diablo, en este mundo? ¿Un inquisidor, un jesuita? No por cierto. Una jesuitesa, una de esas grandes damas arrepentidas, que se cree nacida para gobernar, la cual, en medio de aquel numeroso tropel de temblorosas mujeres, hémela en atormentar a aquellas infortunadas indefensas la ira de sus mal extinguidas pasiones (Jules Michelet, Du prête, de la femme, de la famille, 1845).

A mediados del siglo XIX no era extraño encontrar entre los círculos demo-republicanos de la Europa católica este tipo de comentarios peyorativos hacia las mujeres religiosas, especialmente las monjas de clausura. Desde luego, fueron los años en que anticlericales como Michelet contribuyeron a cimentar esa asociación de las mujeres con la religión, el atraso y el fanatismo en contraposición a aquella otra que vinculaba a los hombres con la ciencia, el progreso y la razón. Esta visión dicotómica de una realidad que verdaderamente era mucho más compleja no sólo ha tenido efectos políticos perversos para la causa feminista, como la negación del voto a las mujeres por estar supuestamente dominadas por sus confesores, sino que ha acabado también por introducirse en el mundo académico. Como denuncian, entre otros autores, Christopher Clark e Inmaculada Blasco, el catolicismo ha sido calificado por numerosos historiadores y sociólogos como una religión netamente antimoderna y eso ha impulsado al movimiento feminista a buscar sus orígenes contemporáneos en espacios ajenos u opuestos al catolicismo. ${ }^{1} \mathrm{Si}$ para la época medieval se ha afirmado que la vida religiosa constituyó un espacio de libertad femenina, ${ }^{2}$ a medida que se fue avanzando hacia la contemporaneidad, la presencia de una Iglesia católica más jerárquica e institucionalizada además de especialmente interesada en el control social y moral de las mujeres ha constituido una importante traba intelectual que ha impedido profundizar en esa relación entre mujeres y religión.

Este trabajo pretende abordar de manera crítica uno de los aspectos más llamativos y patentes de lo que se ha denominado feminización del catolicismo durante el siglo XIX: el aumento considerable de mujeres que decidieron ingresar en la Iglesia como religiosas. Lo haremos desde una doble perspectiva. Por un lado, el análisis del imaginario nos permitirá conocer cómo se construyó culturalmente la figura de la religiosa, en especial la relativamente novedosa para el siglo XIX de la hermana de la caridad. Por otro lado, mediante fuentes de carácter personal nos aproximaremos a la acción de algunas fundadoras y superioras generales de congregaciones femeninas. La autoridad, capacidad de decisión y

1 Clark, C. 2003. "The new catholicism and the European culture wars", en C. Clark; W. Kaiser, Culture wars: secular-catholic conflict in nineteenth-century Europe: 11-46. Cambridge: Cambridge University Press y Blasco, I. 2008. "Sobre historia, religión y género. Algunas reflexiones en torno a las mujeres y el catolicismo en los albores del siglo XX", en L. Serrano-Niza, y Ma B. Hernández Pérez (eds.), Mujeres y religiones. Tensiones y equilibrios de una relación histórica: 319-341. Santa Cruz de Tenerife: Idea.

2 Rivera, Ma M. 2005. "Las beguinas y beatas, las trovadoras y las cátaras: el sentido libre del ser mujer", en I. Morant (dir.), Historia de las mujeres en España y América Latina: vol. I, 745-767. Madrid: Cátedra. libertad de movimientos disfrutadas por estas mujeres han llevado a algunas historiadoras a calificarlas de feministas, una valoración que discutiremos al final del trabajo.

\section{LA FIGURA DE LA RELIGIOSA EN EL IMAGINARIO DE LA ÉPOCA}

Entre las mujeres que decidieron consagrar su vida a Dios durante el siglo XIX, es evidente que las monjas de clausura fueron quienes toparon con una opinión pública más hostil. Desde luego, los cambios políticos, económicos, sociales y culturales provocados por la revolución liberal durante la primera mitad de siglo fueron decisivos para que las monjas fuesen progresivamente concebidas como sujetos anacrónicos y extemporáneos. La mayor importancia otorgada a la maternidad en comparación con centurias anteriores y el hecho de que dedicar una vida a la oración entre los muros de un convento encajara mal con los valores liberal-burgueses del pragmatismo y de la utilidad económica explican esta depreciación social de la figura de la monja de clausura. ${ }^{3}$ Sólo eclesiásticos y publicistas católicos, además de algunos liberales conservadores como Severo Catalina, siguieron alabando el coraje que ellos apreciaban en estas mujeres por encerrarse en un convento, orar "por el mundo" y pedir "misericordia para los impíos y luz para los escépticos". ${ }^{4}$

La novela de carácter anticlerical cultivada por demorepublicanos y socialistas encontró en las figuras de la monja de clausura o de la mujer devota alentada por el sacerdote un buen ejemplo del fanatismo religioso que estos autores tanto criticaban. ${ }^{5}$ El esquema seguido por el republicano catalán Ceferino Tresserra en La judía errante (1862), novela cuyo título remite inequívocamente al exitoso folletín de Eugène Sue publicado en Francia unos años antes, ${ }^{6}$ fue bastante común en este tipo de obras literarias: los jesuitas, presentados como enemigos implacables de la libertad y el progreso, no dudan en seducir a débiles e indefensas mujeres para obligarles a ingresar en fríos y oscuros conventos o internados femeninos. ${ }^{7}$ Incluso una mujer de

3 La conversión en modelo para el conjunto de la sociedad de los valores propios de las clases medias en la España decimonónica ha sido estudiado recientemente en Cruz, J. 2011. The rise of middleclass culture in nineteenth-century Spain. Baton Rouge, Louisiana State University Press.

4 Catalina, S. 1954. La mujer: 116. Buenos Aires: Espasa-Calpe.

5 Salomón, Ma P. 2011. “Devotas, mojigatas, fanáticas y libidinosas. Anticlericalismo y antifeminismo en el discurso republicano a fines del siglo XIX", en A. Aguado y Teresa Ma Ortega, (eds.), Feminismos y antifeminismos. Culturas políticas e identidades de género en la España del siglo xx: 71-98. Valencia: Publicacions Universitat de València.

6 Nos estamos refiriendo lógicamente a Le juif errant, novela publicada por entregas en el periódico Le Constitutionnel entre junio de 1844 y junio de 1845 con enorme éxito.

Otras novelas anticlericales de mediados de siglo que siguen un hilo argumental parecido fueron La criolla y los jesuitas (1845), de Francisco Roballo, Josefina de Comerford o el fanatismo (1849), de Agustín de Letamendi o la trilogía de Wenceslao Ayguals de Izco María la hija de un jornalero (1845), La Marquesa de Bellaflor o el niño de la inclusa (1847) y Pobres y ricos o la bruja de Madrid (1849). Véase al respecto Molina, J. L. 1998. Anticlericalismo y literatura en el siglo XIX. Murcia: Universidad de Murcia. Es interesante señalar que La judía errante y María la hija de un jornalero fueron las únicas novelas españolas que entraron en el Índice de libros prohibidos del Vaticano durante el siglo XIX. 
fuertes convicciones religiosas como Concepción Arenal se mostró muy crítica con las monjas de clausura, cuya vida consideraba no sólo vacía sino también antinatural:

Y ¿ipuede llamarse estado perfecto el de una criatura que no ama, ni piensa, ni trabaja; que así puede definirse la monja? Comprendemos que la perfección en el monje es difícil, pero es posible. Puede ser sabio, puede ser apóstol, puede ser mártir. Aun cabe que se consagre a la ciencia y a la humanidad, que catequice al presidiario o al salvaje, que arrostre la muerte en la epidemia, consolando a un moribundo, o en remotas playas predicando el Evangelio, y que cumpla una alta misión de amor e inteligencia. Pero la mujer reclusa, sin estudios, ni instrucción, ni cuidados, ni quehaceres ni afectos; sin actividad moral e intelectual, ¿cabe que se perfeccione? Más aún, ¿cabe que no se desnaturalice? Hay mucho desconocimiento del corazón humano y de la sabiduría divina en la soberbia pretensión de perfeccionar la naturaleza saliéndose de ella. ${ }^{8}$

No obstante, si tuviésemos que destacar a una religiosa de carne y hueso que generó mucha polémica, y no sólo entre los círculos anticlericales, esta fue María Josefa de Quiroga, más conocida como sor Patrocinio. Nacida en 1811, profesó como Concepcionista a la temprana edad de diecinueve años. Pronto fue conocida por la opinión pública ya que en noviembre de 1835 , en plena guerra carlista, se inició una causa judicial por unas supuestas llagas que aparecían en su cuerpo por cada atentado sufrido por la Iglesia. Desde entonces, fue siempre vinculada a las camarillas más reaccionarias que rodeaban a los reyes, primero a Francisco de Asís, luego a Isabel II. La acusación de intervenir en política desde la sombra le deparó varios destierros de Madrid pero sor Patrocino fue también muy hábil en aprovechar sus poderosos contactos para fundar nuevos conventos en beneficio de su orden religiosa. ${ }^{9}$ Precisamente, la ambición y ansias de poder mostradas por esta monja no sólo despertaron la crítica anticlerical, reflejada de forma cruda y desvergonzada en algunas de las acuarelas que conforman la serie Los Borbones en pelota ${ }^{10}$ sino que también generó ciertas suspicacias entre las más altas jerarquías eclesiásticas, incluido el papa Pío IX. Ante las demandas insistentes

8 Este texto procede de un estudio que Arenal realizó sobre Feijoo en 1876 para concursar en un certamen convocado en Orense en memoria del benedictino. En él, la escritora gallega mostraba su conformidad con Feijoo en el hecho de que su trabajo había contribuido a que se reconociese la igualdad de la mujer. Pero disentía radicalmente del consejo que el benedictino dio a una hermana suya: ingresar en un convento. Su trabajo fue muy polémico y finalmente no se llevó el premio, que recayó en una joven Emilia Pardo Bazán. Fue publicado en el número 218 de Revista de España al año siguiente. La cita procede de Lacalzada, Ma J. 1994. La otra mitad del género humano: la panorámica vista por Concepción Arenal (1820-1893): 101. Málaga: Universidad de Málaga (en cursiva en el original).

9 A pesar de publicarse hace muchos años, todavía resulta útil para conocer algunos detalles de la vida de sor Patrocinio el siguiente libro: Jarnés, B. 1930. Sor Patrocinio. La monja de las llagas. Madrid: Espasa-Calpe. Referencias sobre la influencia de sor Patrocinio en los reyes pueden encontrarse en Ramos, Ma D. 2004. "Isabel II y las mujeres isabelinas en el juego de poderes del liberalismo", en J. S. Pérez Garzón, (ed.), Isabel II: los espejos de la reina: 141-156. Madrid: Marcial Pons y Burdiel, I. 2010. Isabel II: una biografía (1830-1904): 663-669. Madrid: Taurus.

10 SEM. 2012. Los Borbones en pelota (edición de Isabel Burdiel). Zaragoza: Fernando el Católico. de Isabel II por conseguir que su protegida pudiera fundar nuevos conventos y desplazarse libremente por ellos, el pontífice, tan comprensivo con la reina en otros asuntos, se mostró especialmente tajante al negar "autorizar a la superiora a ir de un lado a otro para visitar las casas ya existentes o de nueva fundación". ${ }^{11}$ Como comprobaremos más adelante, Pío IX no fue el único miembro masculino de la Iglesia católica que se alarmó por la relativa autonomía que podían alcanzar algunas religiosas.

En las postrimerías del siglo XIX, Emilia Pardo Bazán se hacía eco de la transformación que estaban experimentando las monjas españolas por "la ineludible marcha de los tiempos":

La monja clásica de antaño, contemplativa, la que cantaba más o menos gangoso, hacía dulces, almendrados, escapularios y acericos [...], va cediendo el paso a la religiosa moderna, más desenfadada y práctica, dedicada preferentemente a la enseñanza o a la caridad activa, deseosa de cierto barniz de ilustración y que aspira a vaciarse en los moldes de las "monjas francesas", las cuales, con los monasterios del Sacre Coeur y otros análogos, han venido a determinar esta evolución en los claustros españoles. Hoy pierden terreno y se van quedando muy solitarios los poéticos conventos viejos, de pura contemplación y ascetismo, con sus triples rejas erizadas de pinchos y su melancólico huerto encerrado entre murallas. Los institutos que reclutan personal, son, como dejo indicado, los medios seculares, que se dedican a cuidar mendigos y enfermos, o a la educación de las señoritas. ${ }^{12}$

Con su pluma ligera y no exenta de ciertas dosis de humor, la escritora gallega llamaba la atención sobre la creciente presencia de las religiosas de vida activa frente a las tradicionales monjas de clausura. En el momento en el que escribió este texto, las primeras se encontraban ya muy próximas de superar a las segundas: 15.669 frente a 19.595 según una estadística de la Nunciatura relativa a $1892 .{ }^{13}$ Sin embargo, este fenómeno se había iniciado unas décadas antes, también en la Europa católica. En Francia, por ejemplo, el incremento de las congregaciones femeninas de vida activa comenzó prácticamente en tiempos de la Revolución. Hasta 1880 se había fundado la nada despreciable cifra de cuatrocientas organizaciones de este tipo en el país galo. ${ }^{14}$ En Italia, el crecimiento congregacionista no despuntó hasta el momento de la unificación. A partir de entonces y, hasta mediados del siglo xx, el número de nuevas congregaciones aumentó a una media de más de tres por año en algunos periodos y estas se concentraron especialmente en el norte, la zona más rica y próspera del país. ${ }^{15}$

11 Carta de Pío IX a Isabel II, Roma, 20 de mayo de 1860, en Gorricho, J. 1966. "Epistolario de Pío IX con Isabel II de España". Archivum Historiae Pontificiae 4: 281-348 (carta en pp. 297-298).

12 Pardo Bazán, E. 1999. La mujer española y otros escritos: 107108 (edición de G. Gómez-Ferrer). Madrid: Cátedra. Este trabajo fue publicado en inglés en la revista Fortnightly Review en 1889 y un año después en castellano en varios números de La España Moderna.

13 Dato recogido de Revuelta, M. 2005. "Clero viejo y clero nuevo en el siglo XIX", en M. Revuelta, La Iglesia española en el siglo XIX. Desafíos y respuestas: 73-111. Madrid: Universidad Pontificia de Comillas.

14 Langlois, C. 1984. Le catholicisme au féminin. Les congrégations françaises à supérieure générale au XIXe siècle. Paris: Cerf.

15 Rocca, G. 1992. Donne religiose. Contributo a una storia della condizione femminile in Italia nei secoli xIX e Xx. Roma: Paoline. 
La situación española guarda más parecidos con el caso italiano que con el francés. Si bien algunas congregaciones destacadas habían sido fundadas ya antes de 1851 (las Carmelitas de la Caridad o las Escolapias, por ejemplo), fue a partir del Concordato firmado ese año entre el Gobierno español y la Santa Sede cuando el fenómeno fundacional se aceleró. Con el nuevo régimen de la Restauración, el proceso continuó a buen ritmo, animado por la llegada de las congregaciones francesas a las que se refería Pardo Bazán. Tras el paréntesis representado por la Segunda República, el franquismo supuso una nueva etapa de esplendor, con la fundación de, como mínimo, cuarenta y cuatro nuevas congregaciones. ${ }^{16}$

Pero, ¿qué eran exactamente las congregaciones femeninas de vida activa? Aunque la Santa Sede tardó un tiempo en homogeneizar la variedad de constituciones y de reglas por las que se regían dichas congregaciones, sí podemos destacar algunos rasgos generales: las congregacionistas se diferenciaban de las monjas de clausura en que no emitían en primera instancia votos solemnes, en que tenían una existencia activa y móvil, en que su actividad era fundamentalmente social (trabajaban preferentemente en escuelas y hospitales), en que estaban teóricamente subordinadas a los obispos (las órdenes religiosas estaban controladas por el clero regular) y, sobre todo, en que sus comunidades estaban bajo control de una superiora general y de una casa madre a diferencia de las comunidades de clausura, que eran autónomas y cada una tenía sus propias reglas de vida en común.

El fenómeno congregacionista se desarrolló en el marco de sociedades progresivamente dominadas por unas relaciones de producción capitalistas donde la denominada cuestión social, esto es, la conciencia de que la pobreza era resultado de un desajuste en el funcionamiento del organismo social, era todavía muy incipiente. ${ }^{17}$ Así pues, ante la pasividad de las estructuras estatales a la hora de hacer frente a los crecientes desequilibrios sociales, las congregacionistas se encargaron de ocupar algunos espacios que luego sí fueron reivindicados más vigorosamente por el Estado: la educación femenina, la asistencia sanitaria y la atención a colectivos en riesgo como los ancianos, las servidoras domésticas o las prostitutas. Aunque era la caridad y no una voluntad sincera por acabar con un orden social tremendamente desigual lo que orientaba la acción de estas mujeres, prácticamente todas las culturas políticas presentes en España a mediados de siglo, desde la antiliberal hasta la demo-republicana, alabaron la figura de la hermana de la caridad. En opinión de Rosa Ríos, este fenómeno no resulta extraño porque las virtudes exigidas a las religiosas -obediencia, humildad, castidad, abnegación y sacrificio- eran las mismas que se consideraban necesarias para las mujeres seglares. ${ }^{18}$ Antonio María Claret, importante figura del clero

16 Valle, A. del. 1996. "Órdenes, Congregaciones e Institutos eclesiásticos femeninos dedicados a la educación y enseñanza”, en B. Bartolomé (dir.), Historia de la acción educadora de la Iglesia en España: vol. II, 512-718. Madrid: BAC.

17 Cabrera, M. A. y Santana, A. 2006. "De la historia social a la historia de lo social". Ayer 62: 165-192.

18 Ríos, R. E. (texto inédito). “El amor sagrado: una pasión ordenada. La representación de la esposa de Cristo en la España de la Restauración". Agradezco a la autora su gentileza por permitirme acceder a este texto. español de la época que escribió varios opúsculos dirigidos a las mujeres, valoraba la labor de apostolado social de las hermanas de la caridad por encima de las mujeres casadas porque su influencia a través de la educación de las niñas era mucho más amplia:

Las casadas, si desde pequeñas han sido bien instruidas, y educadas en la Religión y en sus respectivas obligaciones, joh qué bien tan grande no harán en las casas en donde entren! Ellas serán unos sacerdotes domésticos que santificarán toda la casa; ellas serán unos apóstoles que, como las santas Mónicas, convertirán a sus suegras, maridos, hijos y criados. Mas las que no se casen porque Dios las llame a estado de más perfección, de castidad y continencia perpetua, y se hallen monjas o hermanas dedicadas a la enseñanza, todavía harán el bien en mayor escala que las casadas, pues que no se limitará dentro del breve recinto de una casa, sino que se extenderá por todo el mundo, según la obediencia disponga de ellas. ¡Oh qué apostolado tan santo y provechoso! ${ }^{19}$

Severo Catalina, en el tratado sobre la mujer que he citado anteriormente, dedica un capítulo completo a las hermanas de la caridad, a quienes rinde encendidos elogios. En las últimas líneas de dicho capítulo, Catalina realiza una sintomática conexión entre la madre y la hermana de la caridad: "Los que denigran por sistema al sexo que llaman débil; los que se burlan ridículamente de todas las mujeres, devolviendo quizá a todas la ofensa que una les hizo, que se acuerden de su propia madre; y si no han tenido la dicha de conocerla, que se acuerden de esas criaturas sublimes que son madres de todos los desgraciados y hermanas de la caridad". ${ }^{20}$ También Concepción Arenal insistía en esta relación al opinar que, si bien las hermanas de la caridad no eran madres, sí eran mujeres y, por tanto, estaban dotadas de amor maternal: "La mujer, es mujer aunque no sea madre, es decir, que es compasiva, paciente, afectuosa y dispuesta a la abnegación. Más aún: sin ser madre, tiene afectos maternales. [...] Observemos esas sagradas legiones de Hermanas de la Caridad que amparan a los pobres niños que dejaron huérfanos la muerte, la miseria o el crimen". ${ }^{21}$

Como estamos observando, el hecho de no tener hijos no implicaba, en el imaginario de la época, que una mujer no pudiera desarrollar cualidades maternales. Así, la hermana de la caridad, virgen como el resto de las religiosas, era concebida también como una madre social por su labor caritativa con los más desfavorecidos. En la pintura de temática religiosa de finales de siglo existen varios ejemplos que explotan esta imagen de hermanas de la caridad maternales. Así, en un lienzo de Pedro Rodríguez de la Torre titulado Hermana de la Caridad (1880), aparecen dos figuras femeninas: la primera, en penumbra, es una mujer campesina con un bebé en su regazo mientras que la segunda, en el centro de la imagen, es una monja de delicado rostro que

19 Claret, A. M. 1864. La colegiala instruida. Libro utilísimo y necesario para las niñas: 8-9. Barcelona: Librería Religiosa.

20 Catalina, S. 1954: 120. Estas mismas palabras aparecen reproducidas en un artículo del mismo autor en la Revista Popular, 15 de febrero de 1873.

21 Arenal, C. 1974. "La mujer del porvenir" en C. Arenal, La emancipación de la mujer en España: 181 (edición de M. Armiño). Madrid: Júcar. 
sostiene a otro bebé al que mira con la misma ternura que la aldeana. Por su parte, en Virgen con niño (1904) Jaume Morera representa en primer plano un bebé en una cuna improvisada y, al fondo, la figura desdibujada de una monja. ${ }^{22}$ En ambos casos parece representarse la ansiedad que pudieron experimentar algunas congregacionistas por no ser biológicamente madres a pesar de que socialmente sí eran concebidas como tal.

Incluso un demo-republicano anticlerical como Ceferino Tresserra, que como hemos visto se mostró muy crítico con las mujeres falsamente devotas, escribió una novela cuyo título hace referencia al fundador de las Hijas de la Caridad, la congregación femenina de vida activa más extendida en España a mediados del siglo XIX.. ${ }^{23}$ En Vicente de Paúl o el amor por caridad de Dios, publicada por primera vez en 1867 bajo el pseudónimo de Enrique Werty de Guzmán, aparece un personaje de evidente tono autobiográfico: Ceferina de la Cruz, que era Hija de la Caridad. Mediante ese personaje novelesco, Tresserra establece un paralelismo con su propia trayectoria como apóstol de la idea democrática ya que el espíritu de abnegación, caridad y amor incondicional hacia una idea de estas religiosas coincide con la propia misión regeneradora y benéfica que muestran él y sus correligionarios demócratas. ${ }^{24}$ Peculiar pero, en definitiva, una interpretación más de la evocadora figura de la hermana de la caridad.

RELIGIOSAS EN ACCIÓN. SUPERIORAS GENERALES DE CONGREGACIONES FEMENINAS

Micaela Desmaisières, conocida después como Madre Sacramento y declarada santa en 1934, confesaba en su autobiografía que "tenía un exceso de vida, de energía, que a veces parecía mal en una religiosa" y añadía que era muy criticada por ello. ${ }^{25}$ Como fundadora y Superiora general de una congregación femenina, su caso constituye una buena muestra del intento de los modelos de feminidad dominantes en la época por ocultar la ambición y la relativa autonomía de estas mujeres, tanto mediante la figura de la mujer fanática dominada por su confesor como a través de la imagen cándida e inofensiva de la hermana de la caridad. Los testimonios directos que se han conservado de Sacramento y otras mujeres en situación similar nos ofrecen información muy interesante sobre los motivos que les llevaron a fundar

\footnotetext{
22 Agradezco a Rosa Ríos que me llamara la atención sobre ambas pinturas.

23 Florido, I. 1984. Acción educativa de las Hijas de Caridad en España (1783-1893). Madrid: Hijas de la Caridad de San Vicente de Paúl.

24 Información extraída de Ramos González del Rivero, P. 2008. Las armas de la República europea de las letras: propaganda y pedagogía democráticas en la narrativa popular decimonónica. Ceferino Tresserra: 237. Tesis doctoral, Universidad Autónoma de Madrid. Como señala este autor, la admiración de Tresserra hacia las Hijas de la Caridad posiblemente se debiera a una experiencia personal: haber trabajado como enfermero voluntario junto a monjas de esta congregación en el hospital barcelonés de Hostafranchs durante la epidemia de cólera de 1865.

25 Santísimo Sacramento, M. M. del. Autobiografía: 125. Se cita a partir del texto disponible en Internet: http://www.adoratrices.com/ archivos/biografia/1Autobiografia.pdf [consultado el 20 de febrero de 2013].
}

primero una congregación religiosa y después a promover su expansión como Superioras generales.

La especificidad de las fuentes que se van a utilizar en esta segunda parte del artículo merece un pequeño comentario. Se trata de autobiografías y correspondencia, unas fuentes personales que, en el caso especialmente de las primeras, tienen un carácter construido bastante marcado. ${ }^{26}$ Una autobiografía religiosa como la escrita por la Madre Sacramento el mismo año de su muerte no recoge fehacientemente todo lo que le ocurrió a la autora en su vida hasta el momento de la escritura sino que constituye un relato con episodios intencionalmente seleccionados que pretenden demostrar la convicción y fortaleza de las convicciones religiosas de la autora para que sirvan de ejemplo a otras religiosas y, por qué no, para mostrar sus merecimientos para acceder a la santidad. Sin embargo, la combinación de la autobiografía con la correspondencia enviada y recibida, una fuente generalmente menos retrospectiva, sí nos puede aportar pistas tanto de la subjetividad de sus autoras como de la capacidad de agencia que tuvieron dentro de los condicionantes discursivos existentes a mediados del siglo XIX.

La antropóloga Saba Mahmood y la historiadora Phyllis Mack han estudiado las posibilidades de acción de mujeres con fuertes inquietudes religiosas dentro de sus respectivas confesiones -mujeres musulmanas en Egipto a finales del siglo XX la primera y mujeres cuáqueras en Gran Bretaña durante el siglo XVIII la segunda-. ${ }^{27} A$ través también de fuentes de carácter personal como testimonios orales, cartas o diarios, ambas autoras coinciden en conceptualizar la agencia desde una perspectiva postestructuralista, es decir, concibiendo la acción de los individuos a partir de las condiciones discursivas presentes en un determinado momento histórico. Se oponen así a la asunción normativa liberal según la cual todos los seres humanos tenemos un deseo innato de libertad de tal manera que la agencia humana consiste principalmente en una reacción siempre emancipadora ante un poder siempre coercitivo. Desde luego, este marco teórico resulta muy apropiado para analizar las acciones de las Superioras generales y para no caracterizar a estas últimas como sujetos pasivos por no adoptar una actitud de abierta resistencia frente a las estructuras de poder. Sin embargo, el énfasis en el discurso tampoco nos puede hacer caer en un determinismo exagerado que niegue la capacidad personal de los sujetos para elegir entre las posibilidades discursivas, mayores o menores según el periodo histórico, que tienen a su alcance. En otro lugar ya he analizado en profundidad el modelo de feminidad católico, con sus variantes, que estaba vigente a mediados del siglo $\mathrm{XIX} ;{ }^{28}$ a continuación voy a centrarme en cómo dos mujeres congregacionistas, Micaela Desmaisières y Vicenta María

26 Así se enfatiza en Man, P. 1991. "La autobiografía como desfiguración". Anthropos 29: 113-118.

27 Mahmood, S. 2005. Politics of piety The Islamic Revival and the Feminist Subject: 1-39 Princeton: Princeton University Press y Mack, P. 2003. "Religion, feminism and the problem of agency: Reflections on Eighteenth-Century Quakerism”. Signs, 29-1: 149-177.

28 Mínguez, R. 2012. "Monjas, esposas y madres católicas: una panorámica de la feminización de la religión en España a mediados del siglo XIX". Amnis 11, edición digital: http://amnis.revues.org/1606. 
López y Vicuña, fueron capaces de negociar y aprovechar las posibilidades discursivas de dicho modelo de feminidad en beneficio de sus propias congregaciones.

María Micaela Desmaisières (1809-1865) era una mujer de la aristocracia madrileña que, como otras de su condición social, gustaba de aficiones refinadas como asistir a tertulias, pasear a caballo, acudir al teatro o bailar en palacio con vestidos lujosos a la moda. Tuvo varios pretendientes en su juventud, algunos muy influyentes como el político liberal marqués de Someruelos, pero por circunstancias diversas ninguna de estas relaciones acabó fraguando. Sus hermanos, en cambio, sí consiguieron casarse y Desmaisières quedó al cargo de su madre enferma hasta su muerte en 1841. Soltera y superando ya la treintena, la Vizcondesa de Jorbalán, como así le gustaba que le llamasen en público, se volcó en obras de la caridad y, en compañía de otra mujer aristócrata, fundó en 1845 un colegio destinado a acoger y reeducar a las mujeres que salían del hospital de San Juan de Dios, especializado en enfermedades venéreas. De forma paralela, comenzaron a despertarse en Desmaisières unas inquietudes religiosas que hasta entonces, como se refleja en su correspondencia, habían sido bastante superficiales: sólo alguna apelación retórica a Dios o a la Virgen y felicitaciones onomásticas a sus familiares y amigos. Una persona fue decisiva en su conversión religiosa: el padre Eduardo José Rodríguez de Carasa.

Los ejercicios espirituales que este jesuita gaditano dirigió a la vizcondesa en la primavera de 1847 supusieron un cambio fundamental en la vida de la santa. Desde entonces, Carasa intentó amoldar las formas de comportamiento de Desmaisières a las exigidas por el modelo de feminidad eclesiástico vigente en esa época. ${ }^{29}$ Las cartas que afortunadamente se han conservado dirigidas por Carasa a María Micaela arrojan bastante luz sobre la compleja relación entre el confesor y la confesante. En la mentalidad de eclesiásticos como Carasa o el ya citado Claret, las mujeres solteras, como Desmaisières en ese momento, eran las que generaban más quebraderos de cabeza debido a su inexperiencia y a la relativa autonomía que les aportaba no estar sujetas al lazo conyugal. Además, la vizcondesa era todavía más susceptible de caer en la tentación por su agitada vida social. De ahí que una de las principales preocupaciones de Carasa fuera reducir a la mínima expresión la participación de Desmaisières en eventos públicos con otros miembros de su clase. Los bailes y especialmente los atrevidos vestidos que se llevaban en ellos constituían un asunto especialmente sensible para Carasa. Así, sobre la consulta de Desmaisières de asistir a un baile en Palacio en plena Cuaresma, el padre jesuita respondió lo siguiente:

Me pregunta V. si podrá ir mañana a la noche al concierto de Palacio. Con razón me hace V. esta pregunta, lo uno porque la cuestión no es muy fácil de resolver, en atención a que toda diversión pública en Cuaresma, no es lo más conforme al espíritu de la Iglesia en este santo tiempo, como lo enseñan todos los libros que tratan de esta preciosa materia [...]. Sin embargo, si V. no va por su gusto o

29 Mínguez, R. (en prensa). Evas, Marías y Magdalenas. Género y modernidad católica en la España liberal (1833-1874). Madrid: Centro de Estudios Políticos y Constitucionales. elección, sino por una justa y conveniente condescendencia, aunque no lo apruebo, se lo permito. La otra causa porque (sic) ha hecho V. muy bien en consultarme, es porque, según he oído decir por todo Madrid, en las funciones de Palacio, se presentan las señoras algo menos decentes de lo que es justo. Este es otro punto mucho más delicado que el anterior; porque en él todo es grave y escandaloso y nada, nada se puede permitir. Así lo enseñan todos los autores unánimemente. Por consiguiente, si V. va, que sea muy cubierta y, cuidado, que no vale decir, voy más honesta que otras; sino que es preciso ir con la ropa muy alta por la espalda y por delante. Ya supongo que se reirán de V., pero sepa V. para su consuelo, que esos mismos que se ríen por delante, lo aprueban en su corazón. ${ }^{30}$

El lenguaje utilizado por Carasa, como podemos comprobar, es directo e imperativo, en todas sus cartas se observa una voluntad férrea de sujetar a la vizcondesa con un estrecho marcaje moral. Para hacer frente a las tentaciones de la vida mundana, Carasa intentó reforzar la espiritualidad de la vizcondesa recomendándole que fuera más humilde y que realizara ejercicios para mortificar su cuerpo. Desmaisières debió seguir con tanta devoción estos consejos que llegó a enojar a su confesor, no tanto por los dolores que el uso del cilicio y otros artilugios podían producir en su cuerpo sino por la falta de obediencia que mostraba con su comportamiento: "Tengo que enfadarme con V. por su desobediencia. Sí, por su marcada desobediencia. ¿Quién le ha dado a V. licencia para que se ponga el cilicio en la cintura? ¿Y en la cama? ¡Qué placer!, dice V. ¡Qué propia voluntad! digo yo". ${ }^{31}$

Un año después de sus primeros ejercicios espirituales con Carasa, la conversión de la vizcondesa parecía estar ya bastante avanzada. En una carta dirigida a su criada de confianza, Desmaisières no se sorprendía de que su destinataria se hubiera percatado de los cambios que había experimentado: "No dudo que me halles muy variada en todo y si no adelanto no será por no trabajar para ello, pues es mi ocupación diaria". ${ }^{32}$ Desmaisières no tardó en expresar a su confesor su voluntad de entrar en el estado religioso. Su primera opción fue ingresar en las Hijas de la Caridad de San Vicente de Paúl pero Carasa debía desconfiar de la capacidad de la vizcondesa para mantener el voto de castidad cuando le hizo la siguiente confidencia: "Y no puedo menos de decir a usted, reservadísimamente, que he visto trabajitos, y sé de alguna [hija de la caridad] que se ha salido y se ha casado con el enfermo que había curado". ${ }^{33}$ Tampoco se mostró de acuerdo un tiempo después en que su confesante entrara como monja de clausura en la Orden de la Visitación. Al parecer, la idea que él tenía para la vizcondesa era que se mantuviera al

30 Carasa a M.M. Desmaisières, 24 de febrero de 1849. Archivo Santa Madre Religiosas Adoratrices (ASMRA), Sección II: Correspondencia pasiva, caja 1 .

31 Carasa a M.M. Desmaisières, sin fecha. ASMRA, Sección II: Correspondencia pasiva, caja 1.

32 M.M. Desmaisières a Bernarda Rodríguez, Bruselas, 11 de junio de 1848, en Santísimo Sacramento, M. M. del. 1999. Correspondencia: vol. I (edición de P. Uríbarri y F. Pascual). Madrid: Religiosas Adoratrices. Si no se dice lo contrario, todas las cartas escritas por M.M. Desmaisières que aparezcan en el texto pertenecen a esta edición.

${ }_{33}$ Carasa a M.M. Desmaisières, Madrid, 18 de febrero de 1848. ASMRA, Sección II: Correspondencia pasiva, caja 1. 
frente del colegio de desamparadas que había fundado unos años antes pero sin emitir ningún voto religioso.

Desmaisières finalmente cumplió las expectativas de Carasa cuando decidió quedarse a vivir en el colegio en 1850 a pesar de que, según expresa en su autobiografía, no contase con el beneplácito de su familia: "Me hallaba tan sola, tan triste y despreciada por todos, incluso de mi familia, que no querían saber de mí ni verme". ${ }^{34}$ Desde luego, en esta decisión debieron influir Carasa y otros eclesiásticos con quienes la vizcondesa tenía contacto pero, a tenor de lo manifestado en una carta escrita a su hermano, parece ser que existía también un empeño personal movido por su inspiración religiosa: "Hago al fin la vida que hace años deseo, o mejor dicho, que hace años sigo aunque con mil trabas para seguir mi vocación". ${ }^{35}$

Pero la vocación de la vizcondesa no se frenó ahí. Consciente de que ella sola no podía atender a las prostitutas que ingresaban en su colegio, decidió fundar una congregación para tal fin. En esa tarea no contó en ningún momento con la ayuda de Carasa. Además, varios sacerdotes y obispos trataron de desanimarla de que siguiera adelante, como se puede percibir en estas palabras del arzobispo de Zaragoza: "Aseguro a V.S. que el pensamiento es santo, la caridad que ejercer con las Desamparadas digna de elogio, y laudable el celo de las personas que le ayudan en tan piadosa empresa; pero entre practicar una obra buena y querer elevarla al orden estable y fin sublime de Instituto Religioso, hay una distancia enorme". ${ }^{36}$ Sin embargo, Desmaisières supo aprovechar sus poderosos e influyentes contactos, que incluían a varios políticos y a la propia reina Isabel II, para tener redactadas en 1856 las primeras constituciones de su congregación: las Adoratrices Esclavas del Santísimo Sacramento y de la Caridad.

Un caso que muestra con todavía más claridad la capacidad negociadora de estas mujeres respecto a los modelos de género imperantes a la hora de implantar una nueva congregación religiosa es el de Vicenta María López y Vicuña (1847-1890), fundadora de las Esclavas del Servicio Doméstico. Tras haber sido educada en Madrid en centros prestigiosos como el Colegio de San Luis de los Franceses y haber acompañado durante su adolescencia a su tía María Eulalia en sus tareas caritativas y benéficas, López y Vicuña decidió a los veintiún años fundar un instituto religioso. Sus padres, que vivían en el municipio navarro de Cascante y que ya comenzaban a sufrir los achaques de la edad, se opusieron frontalmente a esta decisión. Las cartas que Vicuña escribió a sus padres, a su confesor el padre Medrano y a otras personas cercanas constituyen excelentes testimonios para conocer los motivos que apartaban a sus padres de la voluntad de su hija. ${ }^{37}$ En primer lugar, despreciaban

34 Santísimo Sacramento, M. M. del. Autobiografía: 88.

35 M.M. Desmaisières a Diego Desmaisières, Madrid, 5 de octubre de 1850 (vol. I).

36 Manuel María García Gil a Sacramento, Zaragoza, 7 de septiembre de 1857. ASMRA, Sección II, Caja 5, L. 1 y 2.

37 La correspondencia de López y Vicuña está impresa y publicada en López y Vicuña, V. M. 1976. Cartas. Madrid: Religiosas de María Inmaculada. Las cartas que cite de López y Vicuña procederán de esta edición. a las mujeres a las que Vicenta María pretendía dedicar el resto de su vida. Como cuenta la protagonista en esta carta escrita al padre Medrano, sus padres preferían incluso que atendiera a las prostitutas antes que a las sirvientas:

Sólo el nombre de criadas les exalta y prorrumpen en mil improperios contra toda esta clase en general. Si tal es su corrupción, razón de más para que necesiten remedio. A esto dicen que lo pongan otra clase de personas, pero no una pobre chica de 21 años. Es tal la prevención que tienen contra ellas, que llegó a decir mi padre, sería mejor cuidar de las arrepentidas, como las Adoratrices. ${ }^{38}$

Vicuña intentó tranquilizar a sus padres informándolos de que no ingresaría en un convento ni se ligaría permanentemente con votos solemnes, lo cual le permitiría visitarlos de vez en cuando. Sin embargo, esto no constituía una razón suficiente para sus padres sino todo lo contrario. Como explica Vicuña a su confesor, "parece que el fundamento sobre el que fundan su oposición es por decir que el modo de vida que me propongo adoptar no es un estado, y que con mis pocos años no pueden dejarme suelta de esa manera, y sin la seguridad que les daría el entregarme a una Orden o Instituto aprobado por la Iglesia". ${ }^{39}$ Efectivamente, sus padres preferían, o al menos así se lo manifestaban a su hija, que ella ingresara en una orden de clausura de las que ya estaban aprobadas antes que involucrarse en la fundación de una congregación que no le libraba de los peligros del mundo. El temor hacia esta renovada forma de vida religiosa es lo que se encontraba detrás de la animadversión de sus padres en este punto. Pero aquello que verdaderamente debía asustar a sus padres era la certeza de que, si Vicenta María continuaba en Madrid con su proyecto fundador, ellos quedarían totalmente desasistidos en Cascante, a cientos de kilómetros de distancia. Apelando a la superioridad del alma frente al cuerpo respondía la futura religiosa a su padre en este asunto:

Dice V. "que venga mi hija a asistir a sus padres, cuya ocupación merece preferencia a la moralización de las sirvientas de Madrid"; no por cierto: V.V. pueden estar perfectamente asistidos sin mí, y mi ausencia puede impedir mucho bien a este número considerable de almas. ¡Ay papá!, si tomara el rumbo que V. desea, segura estoy de que no reclamaba $V$. mi asistencia. Es preciso también que tenga $V$. en cuenta que todo lo que hago aquí es concerniente a la salud espiritual, y V.V. no me necesitan sino para cuidar su salud corporal, y ¿qué comparación tiene el alma con el cuerpo? Si me ocupara de curar las enfermedades físicas de estas muchachas aún podría V. hacer algún argumento, pero me ocupo (aunque indigna e inútil para tal oficio), en evitar pecados. ${ }^{40}$

Parece ser que en la decisión de abandonar a sus padres pudo influir la opinión de Ciriaco Sancha, en ese momento canónigo de Santiago de Cuba y que se había interesado por el proyecto de Vicuña. ${ }^{41}$ Sin embargo, en esta carta escrita

38 Vicuña al padre Victorio Medrano, Cascante, primeros de septiembre de 1868 (vol. I).

39 Vicuña al padre Medrano, Cascante primeros de agosto de 1868 (vol. I).

40 Vicuña a su padre, Madrid 16 de junio de 1868 (vol. I).

41 "Me permito, con su venia, insistir en aconsejarle que no vuelva a casa de sus padres. Entre el atractivo de éstos y la vocación que le ha 
a su tío Manuel María, Vicenta María reconoce el laberinto en el que se encontraba pero confiesa que la ambición de seguir adelante con su proyecto es más poderosa:

Miradas las cosas en el orden natural, todos dicen: ¿cómo dejar a sus padres enfermos para ocuparme de otras obras de caridad? Yo en mis adentros llego a decir otro tanto, y así me hallo en un laberinto, sin saber por dónde girar. Por un lado, parece que la ley de Dios me prescribe ante todo cumplir con los deberes de buena hija; por otro, me tira esa ocupación que constituía toda mi ambición, y más considerando la necesidad de personas que la lleve adelante. ${ }^{42}$

Finalmente, López y Vicuña acabó cumpliendo sus aspiraciones $y$, ante unos padres que no acabaron de aceptar del todo el destino de su hija pero que al menos no lo entorpecieron más, fundó su tan anhelada congregación religiosa en 1876 y permaneció como Superiora general de ésta hasta el final de sus días. Sin duda, Vicenta María fue capaz de contrarrestar el postulado presente en los modelos de feminidad hegemónicos en la época relativo al cuidado que las hijas debían a sus padres con ese otro postulado presente en el discurso católico de género que ofrecía a las mujeres la posibilidad de renunciar a sus deberes familiares en aras de servir a un fin mayor: la recristianización de la sociedad. A pesar de la sujeción moral que, como hemos visto representado en la relación entre Carasa y Desmaisières, caracterizaba al modelo de feminidad eclesiástico, mujeres como Vicuña o la propia Desmaisières supieron también aprovechar las potencialidades que este discurso les ofrecía para desarrollar su capacidad de agencia. Las congregaciones femeninas constituyeron, en ese sentido, un excelente ámbito en el que numerosas mujeres pudieron canalizar sus inquietudes religiosas, sociales y personales.

Uno de los grandes quebraderos de cabeza que estas mujeres tuvieron como Superioras generales fue garantizar el orden dentro de su congregación. Recordemos que el rasgo más destacado de esta forma de organización religiosa era la unidad y solidaridad que existían entre sus comunidades al depender todas ellas de la sede central, donde residía regularmente la Superiora general. Las constituciones de las distintas congregaciones tendieron a favorecer esta estructura organizativa con disposiciones como el nombramiento directo de las superioras locales por parte de la Superiora general. No obstante, las madres superioras de las distintas congregaciones de vida activa no se aseguraron un poder absoluto porque, por ejemplo, no consiguieron en la mayoría de los casos asegurar su privilegiada posición de forma vitalicia. López y Vicuña opinaba que "la perpetuidad cierra del todo la puerta a la ambición, puesto que no hay esperanza sino remotísima de llegar a tal cargo" ${ }^{\prime 43}$ pero el papado

concedido Dios Nuestro Señor no veo fácil amistad ni concordia, y es preciso que sin dilación alguna opte usted por unos u otro. La elección no es dudosa y la tiene usted a la vista con toda evidencia". Carta de Ciriaco Sancha a Vicenta María, 8 de julio de 1868. Reproducida en Prada, M. P. 1975. Vicenta María López y Vicuña. Vida y proyección social de su obra (1847-1890): 53-54. Pamplona: Religiosas de María Inmaculada.

42 Vicuña a su tío Manuel María, Cascante, 13 de noviembre de 1868 (vol. I).

43 Citado en Prada, M.P. 1975: 150. exigió en las constituciones de su congregación, aprobadas finalmente el 13 de enero de 1899, la elección periódica de la Superiora general por parte de las religiosas del instituto.

Mantener la obediencia de las hermanas hacia sus superioras era esencial para el correcto funcionamiento de la congregación y para evitar escándalos que, si salían a la luz pública, podían desprestigiarla notablemente. Así pues, no fueron extraños los llamamientos colectivos de las Superioras generales al respeto del orden y de la jerarquía. Con motivo de la separación de la hermana Asunción Visconti, que había emitido quejas a su dirección, López y Vicuña emitió su primera circular colectiva como Superiora general de la congregación para reafirmar su autoridad y evitar nuevos casos de desobediencia. Aunque el pasaje es largo, considero oportuno recogerlo por la manera en que Vicuña intenta persuadir a las hermanas de su autoridad indiscutible y de la necesidad de mantener el voto de obediencia con constantes preguntas introspectivas, amenazas veladas y llamamientos a dar ejemplo:

¿Mortificamos de tal manera nuestras pasiones que, aunque interiormente experimentemos repugnancia para algunas obediencias, exteriormente ejecutemos la voluntad del superior con presteza, y aun procuremos someter el entendimiento y juicio para obedecer con más perfección?; [...] ¿nos mortificamos de tal manera que, guardando con esmero y constancia el silencio santo, regulamos de tal modo nuestras acciones y palabras, que, lejos de herir con ellas a los demás, demostramos nuestra inocencia, no buscando más que a Dios y no hablando más que de Él, de su ley santa y de sus misericordias con nosotras?... ¿No?... Pues bien, pronto, si no se enmienda la que así obrase, será cortada del árbol de la Religión, bien pronto será expulsada de la casa santa de Dios para habitar en el fuego y las casas de los pecadores. [...] ¿Qué conseguiremos de nuestras acogidas, exhortándolas a la virtud, si no ven en nosotras el ejercicio de ella? ¿Con qué fruto exhortará a la paciencia y caridad y silencio una Hermana, a una o muchas acogidas, si éstas han visto alguna vez irritada y como fuera de sí a dicha Hermana, si la han oído palabras de poca dulzura y caridad, y si han podido observar en la misma habituales faltas de silencio? Mortifiquemos nuestras pasiones interiores, seamos limpias de corazón, y con esto no daremos mal ejemplo a los demás. ${ }^{44}$

El mecanismo más efectivo que estaba a disposición de una Superiora general para mantener bajo control a las distintas comunidades que conformaban su congregación era visitarlas directamente. Además, para fundar una nueva sucursal, era condición imprescindible que la Superiora general se desplazara al lugar donde se iba a establecer para realizar las gestiones directamente. El resultado fue que las Superioras generales de las congregaciones femeninas viajaron mucho, más que la mayoría de las mujeres de su época. La Madre Sacramento fue precisamente una de las que más viajó en sus nueve años como Superiora general de las Adoratrices y ello generó ciertas reticencias en algunos obispos y sacerdotes, alarmados sin duda por la libertad de movimientos de la que podía gozar una congregacionista en comparación con las tradicionales monjas de clausura. Un

44 Carta circular de Vicuña a todas las religiosas de la congregación, Madrid, 9 de julio de 1877 (vol. I). 
buen ejemplo lo constituye esta carta escrita por el obispo de Zamora, Bernardo Conde y Corral, en la que recomienda a Sacramento si no sería mejor que le acompañase un sacerdote en sus viajes en vez de ir sola:

Y esto me pone en la ocasión de indicar a V., valiéndome de la franqueza que me ha inspirado, no sé si la necesidad o la conveniencia de que en sus viajes llevase siempre un sacerdote de su confianza. Es cierto que se viaja con rapidez y conveniencia y que la hidalguía y galantería de los españoles para con las señoras resuelve la mitad de las dificultades que se ofrecen en los viajes. Mas siempre les queda mucho que sufrir si no llevan la compañía de un hombre que dé la cara para tantas y tantas cosas, todas del momento que se necesitan en los viajes. Mudanzas de equipajes, tomar billetes, descanso en las estaciones, esperas indispensables... Hay tantas cosas que un hombre, aunque sea sacerdote, puede hacer por sí mismo en alivio, descanso y decoro de una señora a que ésta no puede echar mano ni atenderse como conviene, que no es posible haya dejado de pensar $V$. en ello muchas veces en sus viajes. $^{45}$

El tono paternalista del obispo de Zamora contrasta sin duda con el que debió utilizar el obispo de Barcelona, Pantaleón Montserrat Navarro. Así se refiere Sacramento a él en la relación de su viaje a la ciudad condal en 1865: "Sé que varias veces ha dicho que estos Colegios no tienen porvenir, que yo no tengo cabeza, que soy una correntona y no pienso más que en viajar y me gusta estar hoy aquí mañana allí". ${ }^{46}$ No parece que esas críticas afectaran demasiado a Sacramento porque en una carta dirigida al Director de la empresa de ferrocarriles de Madrid, Zaragoza y Alicante pidió que los asientos de tren para ella, las hermanas y las colegialas fueran vendidos a mitad de precio. ${ }^{47}$ Esta petición fue finalmente concedida dos meses y medio después. Viajar constituía pues una necesidad de las Superioras generales para poder desempeñar óptimamente su trabajo. Pero también podía ser una actividad placentera. Pocos testimonios reflejan mejor el gusto experimentado por estas mujeres a viajar que la siguiente carta escrita por Vicuña, en la que habla a su padre de su próximo viaje a tierras andaluzas:

Se hace preciso que yo dé una vuelta por la casa de Jerez y lo haré D.M. en breve y la permanencia allí será corta; para mí el viaje es un día de reposo y aun de recreo porque se va con mucha comodidad y ceso de las atenciones indispensables que tengo en cualquiera de las partes en que me hallo; por otra parte la temperatura tan templada de aquel país y la estación favorecen. ${ }^{48}$

Como se puede intuir, el cargo de Superiora general constituía una novedad no fácil de digerir por la masculinizada jerarquía eclesiástica debido no sólo a su libertad de movimientos sino también al poder que una mujer al mando de una congregación podía acumular. Este juego de poderes es claramente perceptible en el complejo proceso de elaboración de las constituciones. Como señala

45 Bernardo Conde a Sacramento, Zamora, 23 de mayo de 1864. ASMRA, Sección II, Caja 5, L. 1 y 2.

46 Santísimo Sacramento, M. M. del: Autobiografía: 191.

47 Sacramento al Director de la empresa de ferrocarriles de Madrid, Zaragoza y Alicante, Madrid, 12 de agosto de 1861 (vol. IV).

48 Vicuña a su padre, Madrid 3 de octubre de 1877 (vol. I).
Ana Yetano, desde la redacción inicial de las constituciones de una congregación hasta su aprobación definitiva, podían transcurrir varios años de cambios y modificaciones continuas en las que intervenían el fundador o fundadora, varios obispos y la Santa Sede. ${ }^{49}$ En el caso concreto de las Adoratrices, se llegaron a redactar hasta tres versiones previas antes de que Roma aprobara las Constituciones definitivas en $1866 .{ }^{50}$ Sacramento tuvo que lidiar en este aspecto con Cirilo Alameda y Brea, arzobispo de Toledo desde 1857. Mediante el análisis de los distintos textos, podemos afirmar que el arzobispo quedó satisfecho al conseguir que el cargo de Superiora general no fuera vitalicio sino renovable cada diez años. Sin embargo, no culminó su aspiración de que el Noviciado de la congregación permaneciera siempre en Madrid, lugar desde el que podía controlar perfectamente la preparación de las futuras Adoratrices, ya que las constituciones definitivas establecieron que la decisión correspondía a la Superiora general bajo licencia de la Santa Sede. Sacramento, por su parte, tuvo éxito en su intención de dotar a la congregación de una estructura jerárquica y centralizada porque una de sus principales aspiraciones, el nombramiento de las superioras locales por la Superiora general y no por elección de las hermanas, fue reconocida en el texto definitivo de las constituciones.

Así pues, un asunto que las Superioras generales tuvieron que cuidar especialmente fue evitar las injerencias externas que podían amenazar la autonomía del instituto. Es verdad que las Superioras generales recurrieron muchas veces a personajes destacados del ámbito civil y eclesiástico en interés o beneficio de su congregación pero fueron poco tolerantes cuando esta colaboración implicaba una contrapartida que podía afectar al orden deseado por ellas para el instituto. El siguiente caso puede servirnos para comprobar cómo podía reaccionar una Superiora general ante lo que consideraba una injerencia sacerdotal en la vida cotidiana de su congregación.

Juan de Dios Montañés era un rico sacerdote valenciano que colaboró estrechamente con Sacramento en la casa que ella fundó en Valencia en 1858. Sus aportaciones económicas y sus contactos con las autoridades locales valencianas fueron decisivos para que esta fundación saliera adelante. Sacramento estuvo muy agradecida por esta actuación pero no tuvo reparos en cortar las alas al citado sacerdote cuando este trató de inmiscuirse en la estrategia a seguir por la congregación. Todo ocurrió en 1863. A finales de julio, Montañés anunció a Sacramento un proyecto relacionado con el local que las Adoratrices ocupaban en el convento de San Gregorio y con el cual el alcalde de Valencia estaba de acuerdo: establecer en la parte baja del edificio una escuela de párvulos servida por dos o tres adoratrices pero retribuida por el Ayuntamiento. ${ }^{51}$ Sacramento respondió rápidamente mostrándose bastante dolida con el sacerdote por tener casi

49 Yetano, A. 2009. "Las congregaciones religiosas femeninas en el siglo XIX. El tema de la obtención de su nuevo estatuto jurídico canónico y su interés historiográfico", Spagna contemporanea 36: 13-43.

50 Lozano, J.M. 1968. Las Adoratrices Esclavas del Santísimo Sacramento y de la Caridad. Constituciones y Espíritu. Madrid, s.e.

51 Montañés a Sacramento, Valencia, 25 de julio de 1863. ASMRA, II, 6 . 
cerrado un proyecto sin conocer ella absolutamente nada. Utilizando como escudo la opinión de los obispos, la Madre superiora expresó su malestar y reivindicó autonomía en la dirección del instituto: "Todos los Prelados están conformes en que no admita nada que ponga trabas a la independencia con que debe obrar la Superiora General, que hoy soy yo, y mañana será otra, y que hombres no convienen en nuestras Casas. Esto es lo que hace que yo diga a V. con franqueza mi opinión, sintiendo disgustar a V. en ello". ${ }^{52}$ Días después, Sacramento volvió a escribir declarando que estaba de acuerdo con establecer una escuela de niñas pobres pero no una de párvulos porque es "una cosa que no entendemos, ni está en armonía con nuestro objeto principal". ${ }^{53} \mathrm{Se}$ justificaba señalando que las escuelas de párvulos eran para ambos sexos y que estaban sujetas a un plan de estudios definido por el Gobierno del que nada sabía.

Montañés se defendió aludiendo a que él no quería entrometerse en los asuntos de la congregación pero como Protector del colegio y cotitular, con Sacramento, del contrato de cesión del edificio por parte del Ayuntamiento, se sentía con suficiente legitimidad para poder decidir él también sobre el uso que había de dar al colegio. ${ }^{54} \mathrm{El}$ sacerdote pudo finalmente cumplir su aspiración inicial pero tuvo que esperar a 1868 para fundar la citada escuela, es decir, tres años después de la muerte de Sacramento.

\section{EPÍLOGO: ¿FEMINISTAS?}

Yvonne Turin, historiadora que ha estudiado a las mujeres congregacionistas de la Francia decimonónica, no duda en calificar a las Superioras generales como "naturalmente feministas":

Ellas son naturalmente feministas, mandan, construyen, educan o mendigan para sus obras, sean pequeñas o inmensas, sin preocuparse en ningún momento sobre el que dirán. Soberanas en sus tierras, no imaginarían ni por un segundo que están usurpando un poder. Ello les obliga a defender sus decisiones. Pero, ¿̇quién, disponiendo de un poder, no está forzado a protegerlo un día sí y otro también, y todavía más cuanto más grande es?. ${ }^{55}$

Turin opina que, para el cargo concreto de Superiora general, era necesario desarrollar unas cualidades especiales porque así lo requería poder gobernar a las decenas de mujeres que formaban parte de una congregación. Las Superioras generales tuvieron que hacer frente a varios retos: la absorción de las comunidades locales dispersas y la creación de otras nuevas, la capacidad de adaptación a las nuevas necesidades requeridas por poderes religiosos o civiles, el buen gobierno de las distintas comunidades a través de visitas o relaciones epistolares, la creación de un noviciado central para moldear futuras monjas a imagen y semejanza de lo que las Superioras querían y la búsqueda

\footnotetext{
52 Sacramento a Montañés, Burgos, 27 de julio de 1863 (vol. V).

53 Sacramento a Montañés, Burgos, 11 de agosto de 1863 (vol. V).

54 Montañés a Sacramento, Valencia, 7 de agosto de 1863. ASMRA, II, 6 .

55 Turin, Y. 1989. Femmes et religieuses au XIX siècle. Le féminisme "en religion": 52. Paris: Nouvelle Cité.
}

constante de fuentes de financiación como las dotes, las donaciones y más tarde los préstamos.

Aunque, en mi opinión, la historiadora francesa acierta en resaltar la dificultad de los desafíos a los que estaban comprometidas las Superioras generales, creo que llamar feministas a estas mujeres constituye una afirmación precipitada y simplista a tenor de los dos casos que he analizado en este trabajo y que pueden ser representativos del colectivo. Desde luego, estamos hablando de mujeres que en ningún momento lograron librarse completamente de la tutela masculina propia de una institución patriarcal como la Iglesia católica, ya fuera en forma de confesores o de obispos. Por otra parte, su visión de la sociedad no era ni mucho menos revolucionaria. Focalizaron su objetivo en atender a los colectivos más vulnerables por las transformaciones económicas del capitalismo emergente pero sin cuestionar en ningún momento el orden social existente. Además, nunca se postularon a favor de lo que en la época se denominaba emancipación femenina a pesar de trabajar preferentemente con mujeres. Todo lo contrario, la misión de Sacramento y Vicuña se centró en reeducar a prostitutas y empleadas del servicio doméstico respectivamente. Con esta acción, las fundadoras mostraban intrínsecamente a sus educandas que eran ellas, y no la sociedad en la que vivían, quienes se encontraban enfermas $y$, por tanto, debían curarse moral y espiritualmente para sobrevivir. Un modo de actuar y de pensar en relación al conjunto de su sexo por parte de estas religiosas que difícilmente puede ser calificado de feminista si entendemos por ello no sólo una postura individual que desafía los sistemas de dominio patriarcal presentes en una determinada época histórica sino también un intento consciente de involucrar a más mujeres en esa lucha.

En realidad, creo que plantear un debate sobre estas mujeres en términos maximalistas (¿eran o no feministas?) resulta verdaderamente baldío por no poderse captar la complejidad de la cuestión ni sus numerosos matices. Sin embargo, sí opino que no pueden menospreciarse aspectos en la vida de las Superioras generales de congregaciones femeninas que tanto las imágenes de la religiosa fanática como de la hermana de la caridad maternal trataron de ocultar. Me refiero a la capacidad de agencia que tuvieron estas mujeres al aprovechar las potencialidades que ofrecía el modelo de feminidad católico vigente en la época a las mujeres que decidían consagrarse a Dios. El hecho de ingresar en la vida religiosa y fundar una congregación femenina obedeció a razones mucho más complejas que una simple manipulación por parte de los confesores. Se debió no sólo a la insatisfacción personal generada por unos discursos de género que denigraban a las mujeres solteras, no casadas con un hombre o con Dios, sino también a una decisión autónoma e interpretada por sus propias protagonistas en términos de ambición y rebeldía frente a lo que otras personas esperaban de ellas. En ese sentido, seguir la llamada de Dios no fue ni mucho menos una decisión que denotara pasividad o sumisión. Ya como Superioras generales, la supervivencia y expansión de sus congregaciones dependieron tanto de su capacidad para reafirmar su autoridad entre las hermanas como de su habilidad para negociar con 
alcaldes, diputados, sacerdotes y obispos mejoras en beneficio de sus institutos pero evitando que ello implicara cualquier tipo de injerencia externa.

En el ámbito propiamente eclesiástico, las mujeres congregacionistas desempeñaron un papel esencial en la respuesta católica a los desafíos planteados por la modernidad liberal. Las congregaciones femeninas de vida activa contribuyeron en gran medida a renovar las anquilosadas estructuras con las que la Iglesia encaró desde principios del siglo XIX los profundos cambios provocados por las revoluciones liberales en varios países. Su contribución al proyecto de recristianización de la sociedad, ideado por la jerarquía eclesiástica, fue decisiva gracias a su carácter capilar y a su capacidad de penetración social. Como maestras de una parte importante de la juventud femenina, las mujeres congregacionistas transmitieron a sus alumnas las funciones naturales que debían ser desempeñadas por una buena esposa y madre católica. Sin embargo, el hecho de que ellas mismas disfrutaran de amplias opciones de realización personal y profesional introdujo importantes fisuras en el modelo de feminidad católico y esto acabó generando las posibilidades discursivas necesarias para que ya en el siglo $x x$ se desarrollara el denominado feminismo católico. ${ }^{56}$ La opinión que el personaje de doña Lupe tiene de Guillermina, alter ego de la Madre Sacramento, en la popular novela de Galdós Fortunata y Jacinta, constituye una buena muestra del carácter emprendedor e incluso "varonil" que para los coetáneos podía tener una mujer congregacionista:

Admirábala mucho, no exclusivamente por sus santidades, sino más bien por aquel desprecio del mundo, por su actividad varonil y la grandeza de su carácter. Quizá la señora de Jáuregui creía sentir también en su alma algo de aquella levadura autocrática, de aquella iniciativa ardiente y de aquel poder organizador, y esta especie de parentesco espiritual era quizá lo que le infundía mayores ganas de tratarla íntimamente. ${ }^{57}$

\section{BiBLIOgRAFÍA}

Arce, R. 2007. Dios, patria y hogar. La construcción social de la mujer española por el catolicismo y las derechas en el primer tercio del siglo Xx. Santander: Universidad de Cantabria.

Arenal, C. 1974. "La mujer del porvenir" en C. Arenal, La emancipación de la mujer en España: 97-188 (edición de M. Armiño). Madrid: Júcar.

Blasco, I. 2003. Paradojas de la ortodoxia. Política de masas y militancia católica femenina en España (19191939). Zaragoza: Prensas Universitarias de Zaragoza.

56 Ostolaza, M. 2012. “Feminismo en religión: las congregaciones religiosas y la enseñanza de la mujer en España, 1851-1930", en Ma $\mathrm{C}$. Marcos del Olmo y R. Serrano García (eds.), Mujer y política en la España contemporánea (1868-1936): 137-158. Valladolid: Universidad de Valladolid; Blasco, I. 2003. Paradojas de la ortodoxia. Política de masas y militancia católica femenina en España (1919-1939). Zaragoza: Prensas Universitarias de Zaragoza y Arce, R. 2007. Dios, patria y hogar. La construcción social de la mujer española por el catolicismo y las derechas en el primer tercio del siglo XX. Santander: Universidad de Cantabria.

57 Pérez Galdós, B. 1980. Fortunata y Jacinta: 534. Madrid: Hernando.
Blasco, I. 2008. "Sobre historia, religión y género. Algunas reflexiones en torno a las mujeres y el catolicismo en los albores del siglo Xx", en L. Serrano-Niza, y Mā B. Hernández Pérez (eds.), Mujeres y religiones. Tensiones y equilibrios de una relación histórica: 319-341. Santa Cruz de Tenerife: Idea.

Burdiel, I. 2010. Isabel II: una biografía (1830-1904). Madrid: Taurus.

Cabrera, M. A. y Santana, A. 2006. "De la historia social a la historia de lo social”. Ayer 62: 165-192.

Catalina, S. 1954. La mujer. Buenos Aires: Espasa-Calpe.

Claret, A. M. 1864. La colegiala instruida. Libro utilísimo y necesario para las niñas. Barcelona: Librería Religiosa.

Clark, C. 2003. "The new catholicism and the European culture wars", en C. Clark; W. Kaiser, Culture wars: secular-catholic conflict in nineteenth-century Europe: 11-46. Cambridge: Cambridge University Press.

Cruz, J. 2011. The rise of middle-class culture in nineteenth-century Spain. Baton Rouge, Louisiana State University Press.

Florido, I. 1984. Acción educativa de las Hijas de Caridad en España (1783-1893). Madrid: Hijas de la Caridad de San Vicente de Paúl.

Gorricho, J. 1966. "Epistolario de Pío IX con Isabel II de España”. Archivum Historiae Pontificiae 4: 281-348.

Jarnés, B. 1930. Sor Patrocinio. La monja de las llagas. Madrid: Espasa-Calpe.

Lacalzada, Ma J. 1994. La otra mitad del género humano: la panorámica vista por Concepción Arenal (1820-1893). Málaga: Universidad de Málaga.

Langlois, C. 1984. Le catholicisme au féminin. Les congrégations françaises à supérieure générale au xixe siècle. Paris: Cerf.

López y Vicuña, V. M. 1976. Cartas. Madrid: Religiosas de María Inmaculada.

Lozano, J.M. 1968. Las Adoratrices Esclavas del Santísimo Sacramento y de la Caridad. Constituciones y Espíritu. Madrid, s.e.

Mack, P. 2003. "Religion, feminism and the problem of agency: Reflections on Eighteenth-Century Quakerism". Signs, 29-1: 149-177.

Mahmood, S. 2005. Politics of piety The Islamic Revival and the Feminist Subject: 1-39 Princeton: Princeton University Press.

Man, P. 1991. "La autobiografía como desfiguración". Anthropos 29: 113-118.

Mínguez, R. 2012. "Monjas, esposas y madres católicas: una panorámica de la feminización de la religión en España a mediados del siglo XIX". Amnis 11: http://amnis.revues. org/1606.

Mínguez, R. (en prensa). Evas, Marías y Magdalenas. Género y modernidad católica en la España liberal (1833-1874). Madrid: Centro de Estudios Políticos y Constitucionales. 
Molina, J. L. 1998. Anticlericalismo y literatura en el siglo XIX. Murcia: Universidad de Murcia.

Ostolaza, M. 2012. "Feminismo en religión: las congregaciones religiosas y la enseñanza de la mujer en España, 1851-1930", en Ma C. Marcos del Olmo y R. Serrano García (eds.), Mujer y política en la España contemporánea (18681936): 137-158. Valladolid: Universidad de Valladolid.

Pardo Bazán, E. 1999. La mujer española y otros escritos (edición de G. Gómez-Ferrer). Madrid: Cátedra.

Pérez Galdós, B. 1980. Fortunata y Jacinta. Madrid: Hernando.

Prada, M. P. 1975. Vicenta María López y Vicuña. Vida y proyección social de su obra (1847-1890. Pamplona: Religiosas de María Inmaculada.

Ramos, Ma D. 2004. "Isabel II y las mujeres isabelinas en el juego de poderes del liberalismo", en J. S. Pérez Garzón, (ed.), Isabel II: los espejos de la reina: 141-156. Madrid: Marcial Pons.

Ramos González del Rivero, P. 2008. Las armas de la República europea de las letras: propaganda y pedagogía democráticas en la narrativa popular decimonónica. Ceferino Tresserra. Tesis doctoral, Universidad Autónoma de Madrid.

Revuelta, M. 2005. "Clero viejo y clero nuevo en el siglo XIX", en M. Revuelta, La Iglesia española en el siglo XIX. Desafíos y respuestas: 73-111. Madrid: Universidad Pontificia de Comillas.

Ríos, R. E. (texto inédito). "El amor sagrado: una pasión ordenada. La representación de la esposa de Cristo en la España de la Restauración".
Rivera, Mạ M. 2005. "Las beguinas y beatas, las trovadoras y las cátaras: el sentido libre del ser mujer", en I. Morant (dir.), Historia de las mujeres en España y América Latina: vol. I, 745-767. Madrid: Cátedra.

Rocca, G. 1992. Donne religiose. Contributo a una storia della condizione femminile in Italia nei secoli xIx e xx. Roma: Paoline.

Salomón, Mạ P. 2011. “Devotas, mojigatas, fanáticas y libidinosas. Anticlericalismo y antifeminismo en el discurso republicano a fines del siglo XIX", en A. Aguado y Teresa Ma Ortega, (eds.), Feminismos y antifeminismos. Culturas políticas e identidades de género en la España del siglo xx: 71-98. Valencia: Publicacions Universitat de València.

Santísimo Sacramento, M. M. del. Autobiografía. http:// www.adoratrices.com/archivos/ biografia/1Autobiografia. pdf.

SantísimoSacramento, M. M. del. 1999. Correspondencia: (edición de P. Uríbarri y F. Pascual). Madrid: Religiosas Adoratrices.

Turin, Y. 1989. Femmes et religieuses au xIxe siècle. Le féminisme "en religion". Paris: Nouvelle Cité.

Valle, A. del. 1996. "Órdenes, Congregaciones e Institutos eclesiásticos femeninos dedicados a la educación y enseñanza", en B. Bartolomé (dir.), Historia de la acción educadora de la Iglesia en España: vol. II, 512-718. Madrid: BAC.

Yetano, A. 2009. "Las congregaciones religiosas femeninas en el siglo XIX. El tema de la obtención de su nuevo estatuto jurídico canónico y su interés historiográfico", Spagna contemporanea 36: 13-43. 